\title{
Recovery and Recycling of Chiral Iridium(N,P Ligand) Catalysts from Hydrogenation Reactions
}

\author{
Marc-André Müller ${ }^{+a, b}$, Stefan Gruber ${ }^{+a, c}$ and Andreas Pfaltz ${ }^{\mathrm{a}, *}$ \\ a Department of Chemistry, University of Basel, St. Johanns-Ring 19, 4056 Basel, Switzerland \\ Phone: +41-61 207-1108, Fax: +41-61 207-1103; E-mail:andreas.pfaltz@unibas.ch \\ b Current address: DSM Nutritional Products Ltd., Research and Development, P.O. Box 2676, 4002 Basel, Switzerland \\ c Current address: Department of Chemistry and Applied Biosciences, ETH Zurich, 8093 Zurich, Switzerland \\ + These authors contributed equally to this work.
}

Received: ((will be filled in by the editorial staff))

Supporting information for this article is available on the WWW under http://dx.doi.org/10.1002/adsc.201\#\#\#\#\#\#

\begin{abstract}
Despite the high efficiency and broad scope of chiral iridium(N,P ligand) complexes as catalysts for asymmetric hydrogenation, the problem of catalyst recovery and recycling has so far attracted little attention. We have found that at the end of a hydrogenation reaction, iridium(N,P ligand) catalysts form dimeric Ir(III) dihydride complexes, which can be converted back to the original precatalysts by addition of COD. Based on these findings, a practically simple protocol for catalyst recovery was devised. The recovered complexes showed essentially the same reactivity and enantioselectivity as the original catalysts. Especially large-scale applications and hydrogenations of less reactive substrates that require high catalyst loadings will benefit from this protocol that allows recovery and reuse of expensive iridium complexes.
\end{abstract}

Keywords: iridium $\cdot$ N,P ligands $\cdot$ asymmetric catalysis $\cdot$ hydrogenation $\cdot$ catalyst recovery

Iridium complexes derived from chiral N,P ligands have emerged as highly effective catalysts for the asymmetric hydrogenation of a wide range of functionalized as well as unfunctionalized alkenes, furans, and imines. ${ }^{[1]}$ In contrast to rhodium- and ruthenium-diphosphine catalysts, ${ }^{[2]}$ they show high reactivity and enantioselectivity towards $\mathrm{C}=\mathrm{C}$ bonds lacking adjacent coordinating groups and, therefore, have significantly broadened the application range of asymmetric hydrogenation.

For large-scale reactions, especially with less reactive substrates that require high catalyst loadings, procedures for catalyst recycling would be desirable. Although the development of strategies for recovery and recycling of homogenous catalysts is an active field of research since many years, ${ }^{[3]}$ the recovery of iridium(N,P ligand) complexes after hydrogenation is essentially unexplored. Only Börner and coworkers $^{[4]}$ reported a recycling protocol using propylene carbonate as solvent. After hydrogenation the product was extracted from the reaction medium with hexane while the catalyst remained in the propylene carbonate layer. However, the scope of this protocol is limited. Reaction rates in propylene carbonate were significantly lower than in $\mathrm{CH}_{2} \mathrm{Cl}_{2}$, resulting in much longer reaction times and in some cases in incomplete conversion, even though only very reactive terminal alkenes were investigated. Solubility issues further restrict application, as the product must be soluble in hexane and possess a partition coefficient that allows extraction from propylene carbonate.

A general problem making catalyst recovery difficult is the instability of the catalytically active Ir complexes present in the reaction medium. ${ }^{[5]}$ Although $\operatorname{Ir}(\mathrm{N}, \mathrm{P}$ ligand)(COD) complexes (e.g. 1 in Scheme 1), which serve as precatalysts, are stable against oxygen and moisture and can be purified by chromatography on silica gel, however, the active species resulting from reaction with dihydrogen are too reactive to be isolated. Thus, in order to recover the catalyst, the Ir complexes present in the reaction medium after hydrogenation must be converted into stable compounds that survive workup and can be used as precatalysts in a subsequent hydrogenation reaction. Here we report a procedure that allows catalyst recovery as COD complex, which displays the same reactivity and enantioselectivity as the original precatalyst.

The incentive to develop such a procedure came from our mechanistic and structural studies of $\mathrm{Ir}$ hydride complexes. NMR experiments revealed that under hydrogenation conditions the resting state in the catalytic cycle is a cationic mononuclear iridium(III)-dihydride alkene complex $\left(\left[\operatorname{Ir}^{\mathrm{III}}(\mathrm{H})_{2}(\text { alkene })(\mathrm{N}, \mathrm{P})\right]^{+}\right) .^{[5 c]}$ In the absence of an alkene substrate, dimeric Ir(III)-dihydride complexes such as $\mathbf{2}$ are observed (Scheme 1). ${ }^{\left[{ }^{5 b}\right]}$ 


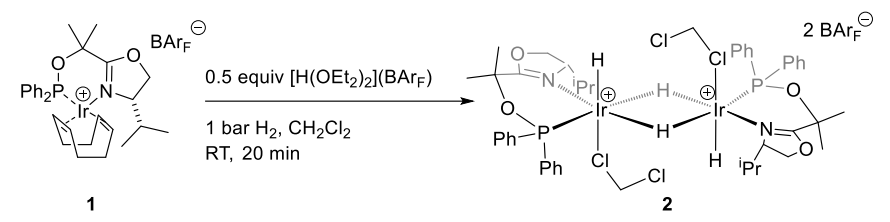

Scheme 1. Selective formation of the dinuclear iridium(III) hydride complex 2 in the presence of $\left[\mathrm{H}_{(}\left(\mathrm{OEt}_{2}\right)_{2}\right] \mathrm{BAr}_{\mathrm{F}}{ }^{[\mathrm{bb}]}$

These complexes are unstable and exhibit a strong tendency to aggregate further to irreversibly form catalytically inactive trinuclear polyhydride clusters. In a preparative experiment the $\operatorname{Ir}(\mathrm{PHOX})$ complex 3 was converted to the trinuclear complex $\mathbf{4}$ in high yield upon treatment with dihydrogen (Eq. 1). ${ }^{[6]}$ Formation of such polyhydride clusters was found to be responsible for catalyst deactivation during hydrogenation reactions using complexes with hexafluorophosphate as counterion. With $\mathrm{BAr}_{\mathrm{F}}\left(\mathrm{BAr}_{\mathrm{F}}\right.$ $=$ tetrakis [3,5-bis(trifluoromethyl)phenyl]borate) and related extremely weakly coordinating anions practically no catalyst deactivation was observed anymore, so high turnover numbers became possible. ${ }^{[7]}$ However, in the absence of an alkene substrate, formation of trinuclear complexes was still observed..$^{[5 b]}$

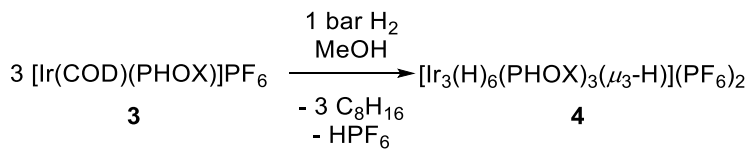

All efforts to convert complex $\mathbf{4}$ back into an catalytically active species failed, ${ }^{[6]}$ implying that the only way to prevent catalyst deactivation is to suppress the formation of polyhydride clusters. We recently found that in the absence of an alkene or other coordinating species, iridium complex 1 was converted almost quantitatively $(>95 \%)$ to the dimeric Ir-hydride complex 2 upon treatment with $\mathrm{H}_{2}$ in the presence of $\left[\mathrm{H}\left(\mathrm{OEt}_{2}\right)_{2}\right] \mathrm{BAr}_{\mathrm{F}}$ (Scheme 1). ${ }^{[5 \mathrm{~b}]}$ Under these acidic conditions, no formation of trinuclear clusters occurred, which according to eq. 1 requires abstraction of a proton from an Ir-hydride intermediate. Complex 2 could be isolated and characterized by NMR and single crystal X-ray analysis. Notably, this dimeric hydride complex showed catalytic activity in the hydrogenation of unfunctionalized olefins; the conversion and enantioselectivity were only slightly lower than with the mononuclear precatalyst $\mathbf{1}^{[5 \mathrm{~b}]}$ Apparently, complex 2 was converted to an active catalyst under hydrogenation conditions. ${ }^{[8]}$ We assumed that under the action of an alkene substrate, dissociation of the dimer and formation a monomeric Ir(alkene) complex occurred, which had been previously characterized as a catalytic intermediate. ${ }^{[5 \mathrm{c}]}$

Based on the observation that under acidic conditions no formation of trinuclear clusters was observed, initial hydrogenation experiments were performed with catalyst $\mathbf{1}$ in the presence of an acid. However, addition of $\left[\mathrm{H}\left(\mathrm{OEt}_{2}\right)_{2}\right] \mathrm{BAr}$, even in catalytic amounts, had a deleterious effect on the selectivity. ${ }^{[9]}$
Assuming that the rate of conversion to inactive trinuclear clusters varies with the ligand structure due to different electronic and/or steric factors, we investigated whether dimeric $\operatorname{Ir}(\mathrm{III})$ dihydride complexes derived from other N,P ligands are less prone to form inactive trinuclear clusters in the absence of substrate under hydrogen gas. Initial hydrogenation experiments with several N,P iridium complexes under hydrogen gas in $\mathrm{CD}_{2} \mathrm{Cl}_{2}$ revealed that the pyridine-based complexes 5 and $\mathbf{6}$ do not form trinuclear complexes. These complexes are very efficient catalysts for the asymmetric hydrogenation of unfunctionalized olefins, in particular complex $(S)$ 5 showed excellent results in the hydrogenation of vitamin $\mathrm{E}$ side chain precursors and $\gamma$-tocotrienyl acetate (Scheme 2). ${ }^{[10]}$

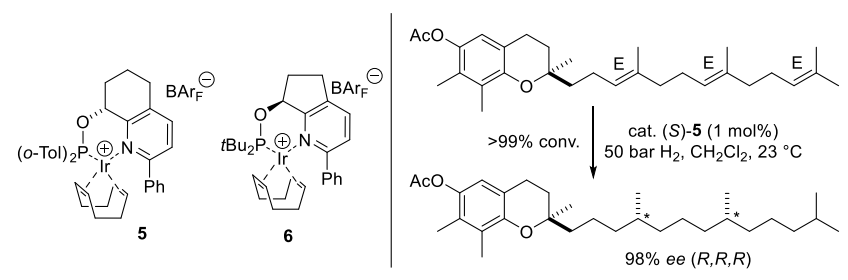

Scheme 2. Examples of pyridine-based iridium complexes and application of complex $(S)-5$ in the hydrogenation of $\gamma$-tocotrienyl acetate.

Treatment of complex 5 with 50 bar of hydrogen gas at room temperature in $\mathrm{CD}_{2} \mathrm{Cl}_{2}$ for 2 hours afforded a new species. Even after longer reaction times under hydrogen gas no significant decomposition of this species or conversion to a polynuclear cluster was observed. The ${ }^{1} \mathrm{H}$ and ${ }^{31} \mathrm{P}$ NMR spectra showed that a single complex had been formed almost exclusively. Based on extended 2D NMR studies its structure was assigned as the dinuclear iridium hydride complex $\mathbf{7}$, bearing in total four hydrides, two bridging hydrides $\left(\mathrm{H}_{\mu \mathrm{a}}\right.$ and $\left.\mathrm{H}_{\mu \mathrm{b}}\right)$ and two terminal hydrides $\left(\mathrm{H}_{\mathrm{t}}\right)$ (Figure 1$)$. The ${ }^{1} \mathrm{H}$ NMR spectrum displayed at triplet at $-3.32 \mathrm{ppm}$ and a multiplet at $-26.98 \mathrm{ppm}$ for the bridging hydrides $\mathrm{H}_{\mu \text { a }}$ and $\mathrm{H}_{\mu \mathrm{b}}$, and a broad singlet at $-30.93 \mathrm{ppm}$ for the terminal hydrides, respectively. The ${ }^{2} J(\mathrm{H}, \mathrm{P})$ values of $80 \mathrm{~Hz}$ for $\mathrm{H}_{\mu \mathrm{a}}$ and $23 \mathrm{~Hz}$ for $\mathrm{H}_{\mu \mathrm{b}}$ are in agreement with structure 7. The low frequency shift of the terminal hydride is characteristic for a structure with a hydride ligand positioned trans to a coordination site which is either vacant or engaged in a $\mathrm{C}-\mathrm{H}$ agostic interaction or loosely bound to a weakly coordinating ligand such as a dichloromethane molecule. ${ }^{[1]}$ The assigned dimeric structure possesses $C_{2}$ symmetry with the two phosphorus atoms oriented in a syn-arrangement. Consequently, the ${ }^{31} \mathrm{P}\left\{{ }^{1} \mathrm{H}\right\}$ NMR spectrum showed a singlet at $86.3 \mathrm{ppm}$.

In addition, a small amount of a different hydride species was observed (see Figure 1). NOESY experiments revealed that this species is in rapid equilibrium with complex 7 . We interpret this finding as an indication that the minor species is a mononuclear iridium dihydride complex, which is formed by partial reversible dissociation of the corresponding dimer $7 .{ }^{[8]}$ 


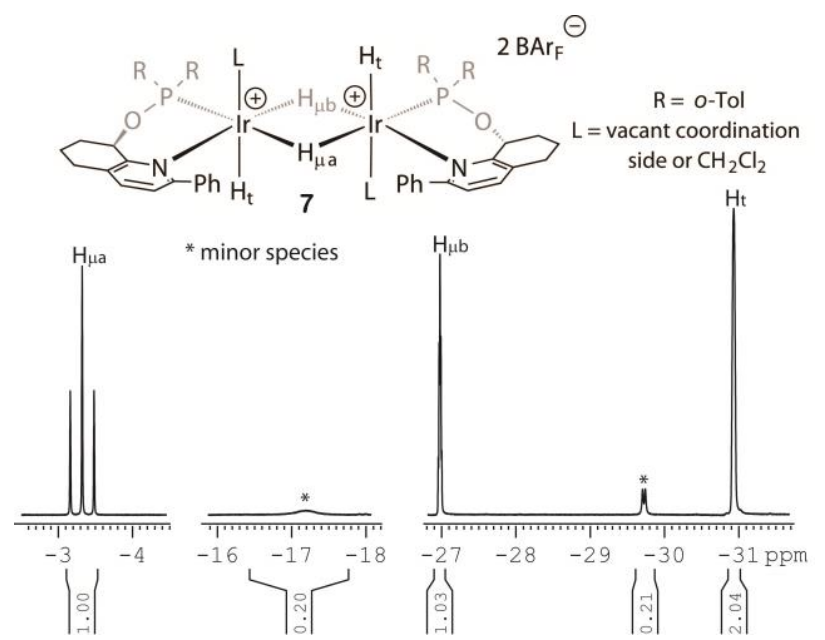

Figure 1. Section of the hydride region showing the hydrides signals of the dinuclear iridium hydride complex 7 and the minor species $(*)$, respectively $(\mathrm{R}=o$-Tol, $\mathrm{L}=$ $\mathrm{CD}_{2} \mathrm{Cl}_{2} ; 295 \mathrm{~K}, 500 \mathrm{MHz}, \mathrm{CD}_{2} \mathrm{Cl}_{2}$ ).

Treatment of complex 6 with 50 bar of hydrogen gas at room temperature in $\mathrm{CD}_{2} \mathrm{Cl}_{2}$ for 2 hours also afforded a new major species with a dynamic structure in solution as indicated by the broadened signals. The ${ }^{1} \mathrm{H}$ NMR spectrum showed two broad hydride signals at -17.64 and $-32.51 \mathrm{ppm}$ in a $1: 1$ ratio. The ${ }^{31} \mathrm{P}\left\{{ }^{1} \mathrm{H}\right\}$ NMR spectrum revealed a broad signal at $136.6 \mathrm{ppm}$ (compared to $141.8 \mathrm{ppm}$ for the COD-precursor). The dynamic nature of this species precluded the elucidation of its structure (monomeric or dimeric form), however, based on the NMR data the formation of a trinuclear cluster could be clearly excluded.

Based on these results, we assumed that after consumption of the substrate, the pyridine-based catalysts would again be present as dimeric or monomeric species, which upon addition of COD could be converted back to the stable COD complexes used as precatalysts. Indeed, addition of COD to the dinuclear iridium hydride complex 7 resulted in complete and clean regeneration of complex 5 (based on NMR analysis), that could be isolated in $84 \%$ yield on a $25 \mathrm{mg}$ scale (Scheme 3).

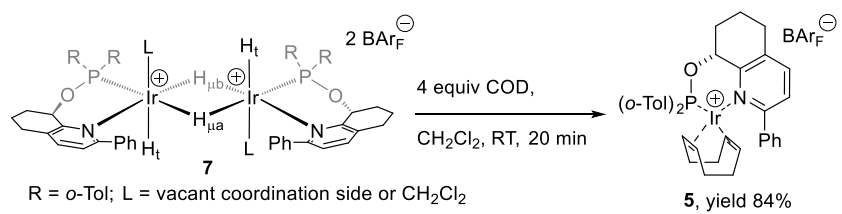

Scheme 3. Regeneration of pyridine-based iridium complex 5 by the addition of COD.

This promising result prompted us to test this approach for recovering the catalyst from the reaction mixture resulting from the hydrogenation of an alkene. Accordingly, the following protocol, which represents a slight modification of a typical hydrogenation procedure, was devised: 1) The substrate was stirred in the presence of $1.0 \mathrm{~mol} \%$ iridium catalyst under 50 bar hydrogen gas for 2 hours; 2) After release of hydrogen gas, 0.1 equiv of COD was added and the reaction mixture was stirred for 1 hour followed by evaporation of the solvent; 3) The residue was separated by a simple filtration over a short plug of silica gel. First the substrate and the excess of COD were eluted with a mixture of pentane/ $\mathrm{Et}_{2} \mathrm{O}$ (1/1), followed by washing the silica gel plug with $\mathrm{CH}_{2} \mathrm{Cl}_{2}$ to obtain the recovered iridium complex. The excess of COD was removed from the hydrogenation product under reduced pressure (Scheme 4).

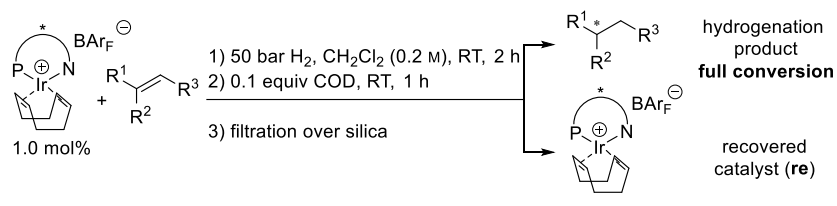

Scheme 4. Protocol applied for the recovery of iridium $\mathrm{COD}$ complexes from hydrogenation reactions.

Following this protocol, we have performed the hydrogenation of $(E, E)$-farnesyl acetone $(\mathbf{8})$, a possible precursor in the synthesis of vitamin $\mathrm{E}$, on a $665 \mathrm{mg}$ scale with $1 \mathrm{~mol} \%$ of catalyst 5 (40 mg). Catalyst 5 was recovered in $70 \%$ yield after the hydrogenation reactions and the fully saturated alkyl ketone was isolated in $99 \%$ yield (entry 1 of Table 1).

Table 1. Recovery of different hydrogenation catalysts from the reaction mixture.

Entry ${ }^{[\mathrm{a}]}$

[a] Reaction conditions: 50 bar $\mathrm{H}_{2}$ pressure, $1.0 \mathrm{~mol} \%$ catalyst, $\mathrm{CH}_{2} \mathrm{Cl}_{2}(0.2 \mathrm{M})$, room temperature, $2 \mathrm{~h}$ reaction time. [b] Full conversion was obtained for all entries; isolated yields of the hydrogenated products were $>95 \%$. [c] $2.50 \mathrm{mmol}$ substrate used. [d] $1.97 \mathrm{mmol}$ substrate used. [e] $1.93 \mathrm{mmol}$ substrate used. [f] $1.45 \mathrm{mmol}$ substrate used. 
To evaluate whether the recovery protocol is also applicable to other $\operatorname{Ir}(\mathrm{N}, \mathrm{P}$ ligand) catalysts, we carried out experiments with catalyst 6, PHOX catalyst 9, and the commercially available ThrePHOX catalyst 10. For these studies (E)-1,2diphenyl-1-propene (11) was used as substrate, since $(E, E)$-farnesyl acetone shows reduced conversion or selectivity with these catalysts. Catalyst $\mathbf{6}$ was recovered in $60 \%$ yield from the hydrogenation reaction (entry 2). This result is in accordance with the previous observation that catalyst $\mathbf{6}$ does not form a trinuclear cluster under hydrogen gas (vide supra). Remarkably, the same protocol also enabled recovery of the PHOX complex 9 in $67 \%$ yield, despite the fact that this catalyst is prone to form a trinuclear complex $^{[6]}$ in the absence of substrate (entry 3 ). In contrast, the ThrePHOX catalyst $\mathbf{1 0}$ could not be recovered by this procedure (entry 4 ).

To compare the enantioselectivity and reactivity of the parent and the recovered catalyst, the PHOXbased complexes 9 and 9re (recovered catalyst) were applied in the hydrogenation of (E)-1,2-diphenyl-1propene (11). The results revealed virtually no difference between the parent and recovered catalyst. At 1.0 and $0.2 \mathrm{~mol} \%$ catalyst loading identical enantiomeric excesses were observed and also the conversion was essentially the same (Table 2).

Table 2. Hydrogenation with original catalyst 9 and a recovered catalyst 9re.

\begin{tabular}{|c|c|c|c|c|}
\hline Entry ${ }^{[a]}$ & Ir-Cat & $\begin{array}{l}\text { Catalyst loading } \\
{[\mathrm{mol} \%]}\end{array}$ & $\begin{array}{l}\text { Conv. } \\
{[\%]^{[\mathrm{b}]}}\end{array}$ & $\begin{array}{l}e e \\
{[\%]^{[\mathrm{c}]}}\end{array}$ \\
\hline 1 & 9 & 1 & $>99$ & $86(R)$ \\
\hline 2 & 9re & 1 & $>99$ & $86(R)$ \\
\hline 3 & 9 & 0.2 & 37 & $87(R)$ \\
\hline 4 & 9re & 0.2 & 40 & $87(R)$ \\
\hline
\end{tabular}

[a] Reaction run on $0.1 \mathrm{mmol}$ scale. [b] Determined by GC analysis. [c] Determined by HPLC analysis on a chiral stationary phase.

In conclusion, NMR studies have demonstrated that at the end of a hydrogenation reaction iridium(N,P ligand) catalysts form dimeric $\operatorname{Ir}(\mathrm{III})$ dihydride complexes after the substrate has been consumed. The stability of these complexes strongly depends on the ligand structure. While hydride complexes derived from phosphinooxazoline complexes such as $\mathbf{9}$ and $\mathbf{1 0}$ are irreversibly converted to catalytically inactive trinuclear Ir clusters after prolonged reaction times, pyridinebased ligand complexes derived from 5 and $\mathbf{6}$ do not form such deactivation products and remain in solution as catalytically active $\operatorname{Ir}(\mathrm{III})$-dihydride dimers. Upon addition of COD the original precatalysts 5 and $\mathbf{6}$ are regenerated. Based on these findings we have devised a practically simple protocol that allows recovery of the catalyst in high purity in $60-70 \%$ yield. Importantly, the recovered COD complex exhibited the same activity and enantioselectivity as the original precatalyst. Unexpectedly, the protocol also worked well for $\operatorname{Ir}(\mathrm{PHOX})$ complex 9, despite its propensity to form inactive Ir clusters. On the other hand, the Ir(ThrePHOX) catalyst 10 could not be recovered. Although this protocol does not seem applicable to all catalysts, it should be of practical value considering the promising results obtained with pyridine-based ligand complexes, which are the catalysts of choice for many important substrate classes. Especially large-scale applications and hydrogenations of less reactive substrates that require high catalyst loadings will benefit from this protocol that allows recovery and reuse of expensive iridium complexes.

\section{Experimental Section}

Procedure for the hydrogenation of (E,E)-farnesyl acetone (8) and subsequent recovery of catalyst 5: A glass inlet of an autoclave was charged with iridium catalyst $5(40 \mathrm{mg}$, $1.0 \mathrm{~mol} \%)$ and then $(5 E, 9 E)$-farnesylacetone $(8,656 \mathrm{mg}$, $2.50 \mathrm{mmol})$ dissolved in $\mathrm{CH}_{2} \mathrm{Cl}_{2}(12.5 \mathrm{~mL}, 0.2 \mathrm{M})$ was added under normal atmosphere. The glass inlet was placed in an autoclave that was purged with argon and then pressurized to 50 bar with $\mathrm{H}_{2}$. The reaction mixture was stirred for $2 \mathrm{~h}$ at room temperature (magnetic stir bar, $700 \mathrm{rpm}$ ). The autoclave was opened under normal atmosphere and the reaction mixture was transferred to a round bottom flask, which had been previously purged with argon for $5 \mathrm{~min}$. 1,5-Cyclooctadiene (0.1 equiv.) was added and the reaction mixture was stirred for $1 \mathrm{~h}$ at room temperature under argon. All volatiles were evaporated under reduced pressure $\left(700 \mathrm{mbar} \rightarrow 10 \mathrm{mbar}, 40{ }^{\circ} \mathrm{C}\right)$, whereby most of the COD was removed. The residue was purified by column chromatography (silica gel $\mathrm{d} \times \mathrm{h}: 2 \mathrm{~cm}$ $\times 8 \mathrm{~cm})$ by first eluting the hydrogenated product with $\mathrm{Et}_{2} \mathrm{O} /$ pentane $(1 / 1)(\sim 100 \mathrm{~mL})$, followed by eluting the catalyst with $\mathrm{CH}_{2} \mathrm{Cl}_{2}(\sim 60 \mathrm{~mL})$. The separate fractions were concentrated in a rotary evaporator (700 mbar $\rightarrow 10$ mbar, $\left.40^{\circ} \mathrm{C}\right)$ and dried under high-vacuum $\left(\sim 10^{-1} \mathrm{mbar}, 30\right.$ $\mathrm{min}, \mathrm{rt}$ ) to afford the hydrogenated product free of COD in $99 \%$ yield $(663 \mathrm{mg})$ and the recovered catalyst 5 in $70 \%$ yield $(28 \mathrm{mg})$, respectively.

Procedure for the hydrogenation (E)-1,2-diphenyl-1propene (11) and subsequent recovery of catalyst 6: A glass inlet of an autoclave was charged with iridium catalyst $6(30 \mathrm{mg}, 1.0 \mathrm{~mol} \%)$ and then $(E)$-1,2-diphenyl-1propene $(11,382 \mathrm{mg}, 1.97 \mathrm{mmol})$ dissolved in $\mathrm{CH}_{2} \mathrm{Cl}_{2}(10$ $\mathrm{mL}, 0.2 \mathrm{M}$ ) was added under normal atmosphere. The glass inlet was placed in an autoclave that was purged with argon and then pressurized to 50 bar with $\mathrm{H}_{2}$. The reaction mixture was stirred for $2 \mathrm{~h}$ at room temperature (magnetic stir bar, $700 \mathrm{rpm}$ ). The autoclave was opened under normal atmosphere and the reaction mixture was transferred to a round bottom flask, which had been previously purged with argon for $5 \mathrm{~min}$. 1,5-Cyclooctadiene (0.1 equiv) was added and the reaction mixture was stirred for $1 \mathrm{~h}$ at room 
temperature under argon. All volatiles were evaporated under reduced pressure (700 mbar $\rightarrow 10 \mathrm{mbar}, 40{ }^{\circ} \mathrm{C}$ ), whereby most of the COD was removed. The residue was purified by column chromatography (silica gel $\mathrm{d} \times \mathrm{h}: 2 \mathrm{~cm}$ $\times 5 \mathrm{~cm})$ by first eluting the hydrogenated product with $\mathrm{Et}_{2} \mathrm{O} /$ pentane $(1 / 1)(\sim 100 \mathrm{~mL})$, followed by eluting the catalyst with $\mathrm{CH}_{2} \mathrm{Cl}_{2}(\sim 40 \mathrm{~mL})$. The separate fractions were concentrated in a rotary evaporator $(700 \mathrm{mbar} \rightarrow 10$ mbar, $\left.40^{\circ} \mathrm{C}\right)$ and dried under high-vacuum $\left(\sim 10^{-1}\right.$ mbar, 30 $\min , \mathrm{rt})$ to afford the hydrogenated product free of COD in $99 \%$ yield $(381 \mathrm{mg})$ and the recovered catalyst 6 in $60 \%$ yield (18.1 mg), respectively.

For the hydrogenation of (E)-1,2-diphenyl-1-propene (11) with catalysts 9 and $\mathbf{1 0}$ and recovery of those, the same procedure as described for catalyst $\mathbf{6}$ was applied, using $1.93 \mathrm{mmol}$ and $1.45 \mathrm{mmol}$, respectively, of $(E)-1,2-$ diphenyl-1-propene (11).

The analytical data of the recovered catalyst $5,{ }^{[12]} \mathbf{6},{ }^{[12]}$ and $\mathbf{9}^{[13]}$ and the hydrogenation products propane-1,2diyldibenzene ${ }^{[14]} \quad$ and $\quad(6 R, 10 R)-6,10,14-$ trimethylpentadecan-2-one ${ }^{[15]}$ are consistent with literature values.

\section{Acknowledgements}

We are thankful to Achim Link for synthetic contributions. Support by the Swiss National Science Foundation is gratefully acknowledged

\section{References}

[1] a) X. Cui, K. Burgess, Chem. Rev. 2005, 105, 32723296; b) S. J. Roseblade, A. Pfaltz, Acc. Chem. Res. 2007, 40, 1402-1411; c) T. L. Church, P. G. Andersson, Coord. Chem. Rev. 2008, 252, 513-531; d) D. Woodmansee, A. Pfaltz, Top. Organomet. Chem. 2011, 34, 31-76; e) D. H. Woodmansee, A. Pfaltz, Chem. Commun. 2011, 47, 7912-7916; f) A. Cadu, P. G. Andersson, J. Organomet. Chem. 2012, 714, 3-11; g) J. J. Verendel, O. Pàmies, M. Diéguez, P. G. Andersson, Chem. Rev. 2014, 114, 2130-2169; h) O. Pàmies, M. Magre, M. Diéguez, Chem. Rec. 2016, 16, 1578-1590; i) C. Margarita, P. G. Andersson, J. Am. Chem. Soc. 2017, 139, 1346-1356.

[2] a) G. Shang, W. Li, X. Zhang, in Catalytic Asymmetric Synthesis (Ed.: I. Ojima), John Wiley \& Sons, Inc., 2010, pp. 343-436; b) D. J. Ager, A. H. M. de Vries, J. G. de Vries, Chem. Soc. Rev. 2012, 41, 3340-3380.

[3] a) D. J. Cole-Hamilton, Science 2003, 299, 1702-1706; b) D. E. De Vos, I. F. J. Vankelecom P. A. Jacobs Chiral Catalyst Immobilization and Recycling, WileyVCH, Weinheim, 2007; c) A. F. Trindade, P. M. P. Gois, C. A. M. Afonso, Chem. Rev. 2009, 109, 418514; d) G. Chauhan, K. K. Pant, K. D. P. Nigam, Ind. Eng. Chem. Res. 2013, 52, 16724-16736.

[4] J. Bayardon, J. Holz, B. Schäffner, V. Andrushko, S. Verevkin, A. Preetz, A. Börner, Angew. Chem., Int. Ed. 2007, 46, 5971-5974.
[5] For studies of N,P derived iridium-dihydride complexes, see: a) C. Mazet, S. P. Smidt, M. Meuwly, A. Pfaltz, J. Am. Chem. Soc. 2004, 126, 14176-14181; b) S. Gruber, M. Neuburger, A. Pfaltz, Organometallics 2013, 32, 4702-4711; c) S. Gruber, A. Pfaltz, Angew. Chem., Int. Ed. 2014, 53, 1896-1900; d) Y. Liu, I. D. Gridnev, W. Zhang, Angew. Chem., Int. Ed. 2014, 53, 1901-1905; e) S. Gruber, Organometallics 2016, 35, 699-705; f) M.-L. Li, S. Yang, X.-C. Su, H.-L. Wu, L.-L. Yang, S.-F. Zhu, Q.-L. Zhou, J. Am. Chem. Soc. 2017, 139, 541-547

[6] S. P. Smidt, A. Pfaltz, E. Martínez-Viviente, P. S. Pregosin, A. Albinati, Organometallics 2003, 22, 10001009.

[7] S. P. Smidt, N. Zimmermann, M. Studer, A. Pfaltz, Chem.-Eur. J. 2004, 10, 4685-4693.

[8] Gridnev and co-workers have shown by lowtemperature NMR studies that N,P derived hydridebridged dinuclear iridium pentahydride complexes equilibrate in solution via a hydride-bridged dinuclear iridium tetrahydride complex to mononuclear dihydride iridium(III) complexes of the forumula $\left[\operatorname{Ir}(\mathrm{H})_{2}(\mathrm{BiphPHOX})\right] \mathrm{BAr}_{\mathrm{F} .} ;$ see ref [5d]

[9] In the hydrogenation of $(E)$-1,2-diphenyl-1-propene with $0.1 \mathrm{~mol} \%$ of catalyst $\mathbf{1}$, similar conversion but lower enantioselectivity was observed using $0.2 \mathrm{~mol} \%$ $\left[\mathrm{H}\left(\mathrm{OEt}_{2}\right)_{2}\right] \mathrm{BAr} F$ as additive. The ee dropped from $92 \%$ to $78 \%$ while conversion reached $10 \%$ and $12 \%$, respectively (50 bar $\mathrm{H}_{2}$, RT, 2 h).

[10] a) S. Bell, B. Wüstenberg, S. Kaiser, F. Menges, T. Netscher, A. Pfaltz, Science 2006, 311, 642-644; b) A. Wang, B. Wüstenberg, A. Pfaltz, Angew. Chem., Int. Ed. 2008, 47, 2298-2300.

[11] We have recently reported two structures with the formula $[\operatorname{IrH}(\mathrm{C}, \mathrm{N})(\mu-\mathrm{H})]_{2}\left(\mathrm{BAr}_{\mathrm{F}}\right)_{2}$ with a hydride shift trans to an empty coordination site appearing at $\delta=$ 36.85 and -34.45 ppm, respectively; See ref. [5b]. See also: a) H. E. Selnau, J. S. Merola, Organometallics 1993, 12, 3800-3801; b) N. M. Scott, V. Pons, E. D. Stevens, D. M. Heinekey, S. P. Nolan, Angew. Chem. Int. Ed. 2005, 44, 2512-2515; c) M. R. Castillo, M. Mart_n, J. M. Fraile, J. A. Mayoral, E. Sola, Angew. Chem. Int. Ed. 2011, 50, 3240 - 3243. For a structure with a hydride ligand positioned trans to a dichloromethane molecule with the formula $\left[\mathrm{IrH}\left(\mathrm{CH}_{2} \mathrm{Cl}_{2}\right)(\mathrm{N}, \mathrm{P})(\mu-\mathrm{H})\right]_{2}\left(\mathrm{BAr}_{\mathrm{F}}\right)_{2}$; See ref. [5b].

[12] S. Kaiser, S. P. Smidt, A. Pfaltz, Angew. Chem., Int. Ed. 2006, 45, 5194-5197

[13] V. Semeniuchenko, V. Khilya, U. Groth, Z. Naturforsch. $B, 2009,64,1147-1158$.

[14] C. E. Hartmann, V. Jurcik, O. Songis, C. S. J. Cazin, Chem. Commun. 2013, 49, 1005-1007.

[15] T. Suga, S. Ohta, A. Nakai, K. Munesada, J. Org. Chem. 1989, 54, 3390-3393. 


\section{COMMUNICATION}

Recovery and Recycling of Chiral Iridium(N,P

Ligand) Catalysts from Hydrogenation Reactions

Adv. Synth. Catal. Year, Volume, Page - Page

Marc-André Müller, Stefan Gruber and Andreas Pfaltz*

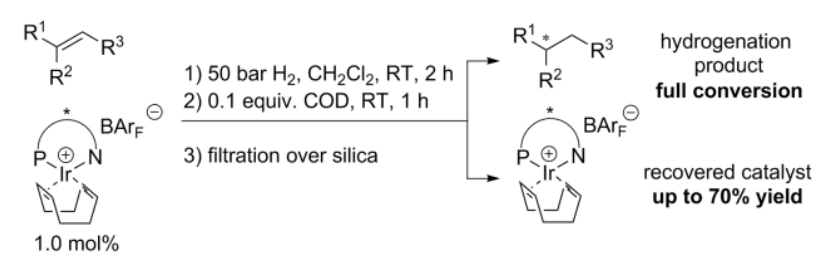

